\title{
Jute/polypropylene Composites: Effect of Enzymatic Modification on Thermo-mechanical and Dynamic Mechanical Properties
}

\author{
Xiaoyan $\mathrm{Ni}^{1}$, Aixue Dong ${ }^{1}$, Xuerong Fan ${ }^{1,2}$, Qiang Wang ${ }^{1,2 *}$, Yuanyuan $\mathrm{Yu}^{1}$, and Artur Cavaco-Paulo ${ }^{2,3}$ \\ ${ }^{1}$ Key Laboratory of Science and Technology of Eco-Textile, Ministry of Education, Jiangnan University, \\ Wuxi 214122, Jiangsu, China \\ ${ }^{2}$ International Joint Research Laboratory for Textile and Fiber Bioprocesses, Jiangnan University, \\ Wuxi 214122, Jiangsu, China \\ ${ }^{3}$ Department of Biological Engineering, University of Minho, Campus de Gualtar, Braga 4710-057, Portugal
}

(Received June 24, 2015; Revised August 10, 2015; Accepted August 19, 2015)

\begin{abstract}
In this study, a high-performance composite was prepared from jute fabrics and polypropylene (PP). In order to improve the compatibility of the polar fibers and the non-polar matrix, alkyl gallates with different hydrophobic groups were enzymatically grafted onto jute fabric by laccase to increase the surface hydrophobicity of the fiber. The grafting products were characterized by FTIR. The results of contact angle and wetting time showed that the hydrophobicity of the jute fabrics was improved after the surface modification. The effect of the enzymatic graft modification on the properties of the jute/PP composites was evaluated. Results showed that after the modification, tensile and dynamic mechanical properties of composites improved, and water absorption and thickness swelling clearly decreased. However, tensile properties drastically decreased after a long period of water immersion. The thermal behavior of the composites was evaluated by TGA/DTG. The fiber-matrix morphology in the modified jute/PP composites was confirmed by SEM analysis of the tensile fractured specimens.
\end{abstract}

Keywords: Jute/PP composites, Laccase, Alkyl gallates, Hydrophobic modification, Tensile, Thermal and dynamic mechanical properties

\section{Introduction}

Growing environmental responsiveness has led a considerable interest in using natural fibers as reinforced materials of polymer-based composites. Natural bast fibers like hemp, sisal, ramie and jute offer a number of benefits since they have specific strength and stiffness, low density, low cost, renewability, and biodegradability [1,2]. Among the natural fibers, jute is recognized as one of the most attractive reinforcement due to its high strength and modulus [3]. It is also noted that jute is relatively inexpensive and commercially available in a required form.

However, the lack of strong adhesion to most polymeric matrices has prevented the extended utilization of jute fibers due to its high moisture absorption tendency and poor wettability [4]. Natural fibers are hydrophilic and possess polar functional group, while most of the thermoplastic polymers are hydrophobic and have non-polar functional groups [5]. In order to improve the interfacial bonding between the fibers and polymer matrix, either physical or chemical modifications on the surfaces of fibers or the polymer matrix have been developed [6-10]. Moreover, the utilization of coupling agents as the bridges between fibers and matrix was also presented as an attractive method for improving compatibility of fibers with polymer chains [11].

In recent years, biocatalytic technologies find expanding applications in the modification and processing of textile

*Corresponding author: qiang_wang@163.com materials owing to the eco-friendly nature and mild conditions. Various enzymes such as laccase have been used in industrial processes. Laccase ( $p$-diphenol: oxygen oxidoreductase, EC 1.10.3.2) belongs to copper-containing oxidases, which catalyze reduction of molecular oxygen to water, bypassing hydrogen peroxide formation $[12,13]$. The reaction usually involves oxidation of lignin moieties on the jute surface to create a radical-rich reactive surface to which oxidized (radicalcontaining) or non-oxidized molecules of interest can be grafted. The alkyl gallates, having a molecular structure composed of a hydrophilic head (phenolic ring) and a hydrophobic alkyl chain, have been successfully grafted on wool by laccase to produce a textile material with antimicrobial, antioxidant and water repellent properties [14]. In our previous work, dodecyl gallate was enzymatically grafted onto the jute fabric by laccase to improve the hydrophobicity of jute [15]. However, as far as we know, there is no attempt regarding the effect of chain length upon the hydrophobicity of jute and the properties of modified jute reinforced composites.

In the current work, alkyl gallates with different aliphatic chain length, such as propyl gallate (PG), octal gallate (OG) and dodecyl gallate (DG) were enzymatically grafted onto jute fabric by laccase to increase the surface hydrophobicity of the fiber. The schematic illustration of the reaction is presented in Figure 1. In addition, the influence of alkyl chain length on the water absorption, thermal, tensile and dynamic mechanical properties of the jute/PP composites was investigated. 


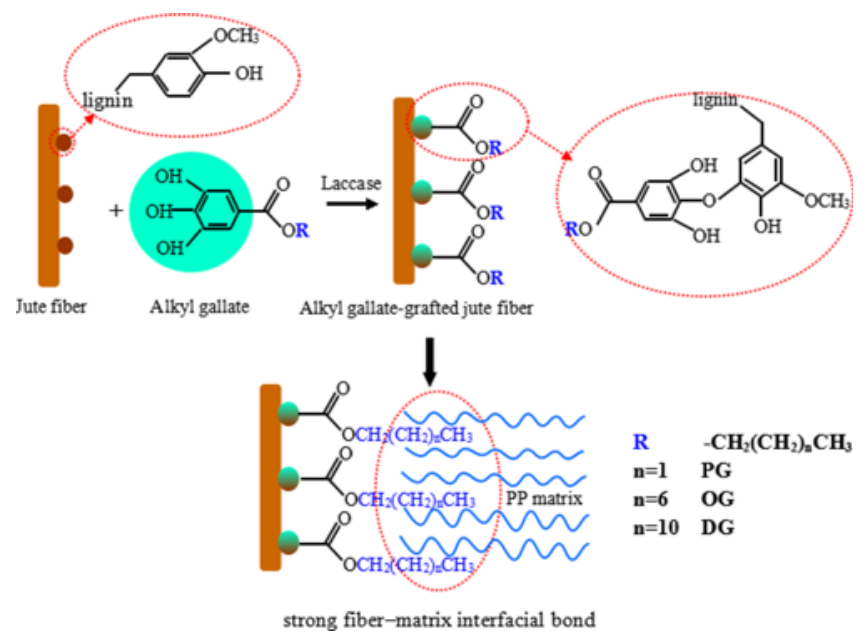

Figure 1. Schematic illustration of laccase-catalyzed grafting reaction of alkyl gallate onto the jute fabric.

\section{Experimental}

\section{Materials}

Jute fabrics $(100 \%)$ with an average area weight of $0.0417 \mathrm{~g} / \mathrm{cm}^{2}$ were supplied by Longtai weaving Co., Ltd. (Changshu, China). Laccase (Denilite II) with an activity of $45 \mathrm{U} / \mathrm{g}$ from Aspergillus was provided by Novozymes (Shanghai, China). Propyl gallate (PG) $\left(M_{W}=212.21\right)$, octal gallate (OG) $\left(M_{W}=282.33\right)$ and dodecyl gallate (DG) $\left(M_{W}=\right.$ 338.44) (98\% purity, chemical structures of all these alkyl gallates in Figure 1) were obtained from J\&K Technology Co., Ltd. (Beijing, China). Polypropylene (PP) spunlace nonwoven cloth obtained from Yonghui textile technology limited company (Yangzhou, China) was used in this study. It has an area density of $0.0142 \mathrm{~g} / \mathrm{cm}^{2}$, and melting temperature of $164{ }^{\circ} \mathrm{C}$. All other reagents were purchased from Sinopharm Chemical Reagent Co. Ltd. (Shanghai, China) and were of analytical grade.

\section{Pretreatment of Jute Fabrics}

The jute fabrics were Soxhlet-extracted with a 2:1 mixture of benzene and ethanol at $90{ }^{\circ} \mathrm{C}$ for $12 \mathrm{~h}$ to remove lipophilic extractives, followed by boilling with distilled water for $3 \mathrm{~h}$. Therefore, more lignins were exposed on the surfaces of the jute fibers.

\section{Hydrophobic Modification of Jute Fabrics}

Jute fabrics were immersed in the solutions of laccase $(2.5 \mathrm{U} / \mathrm{ml})$ for $10 \mathrm{~min}$, and then incubated for $4 \mathrm{~h}$ in the presence of PG, OG and DG $(10 \mathrm{mM})$ in a shaking bath, respectively. The reaction was allowed to proceed in $80 / 20$ (v/v\%) of $0.2 \mathrm{M}$ acetate buffer/EtOH solutions with a fabricto-liquor ratio of 1:50 at $\mathrm{pH} 3.5$ and $50{ }^{\circ} \mathrm{C}$. After the reaction, the jute fabrics were first rinsed with deionized water at $80^{\circ} \mathrm{C}$ for $20 \mathrm{~min}$, then washed with water, and then air-dried.
Finally, the jute fabrics were Soxhlet-extracted with acetone at $75^{\circ} \mathrm{C}$ for $12 \mathrm{~h}$.

\section{Manufacturing of Composite Laminates}

A hand lay-up technique was used to prepare jute/PP composite samples. PP nonwoven cloth (three layers) and pre-weighted jute fabrics (two layers) in a mass ratio of $1: 1$ were placed alternately (sandwich method) in a mold. Then the prepared sandwich was compressed in the heat press under a pressure of $4 \mathrm{MPa}$ and at $180^{\circ} \mathrm{C}$ by using hot pressing for $5 \mathrm{~min}$. The composites were then removed from the mold and cured at room temperature for further use.

\section{Fourier Transformation Infrared Spectroscopy (FTIR) Analysis}

FTIR spectra of control and alkyl gallates modified jute fabrics were recorded using using a Nicolet iS10 FT-IR spectrometer (Thermo Fisher Scientific, USA) with the ATR technique. Each spectrum was obtained by coadding 16 scans with a resolution of $4 \mathrm{~cm}^{-1}$ with the range of 4000 $650 \mathrm{~cm}^{-1}$.

\section{Contact Angle Measurements}

In order to study the hydrophobic property of jute, contact angles were measured using a SL200B static contact angle/ interfacial tension meter (Kino Industry Co, USA). A drop of water $(2 \mu l)$ was dropped on jute fabric samples through a micro-syringe. At least five measurements were taken from different areas on sample surface and the results were averaged.

\section{Dimension Stability Test}

The water absorption and thickness swelling were determined in accordance with ASTM D 5229. Before testing, the weight and thickness of each composite sample $(100 \mathrm{~mm} \times$ $20 \mathrm{~mm} \times 1 \mathrm{~mm}$ ) were measured. Each type of composite samples was immersed in distilled water at room temperature for $24 \mathrm{~h}$, and then taken out and wiped with filter paper to remove surface water before measurement of weight and thickness. The samples were re-immersed in water to continue sorption until saturation. The dimension stability test continued for several days until constant weight of a sample was attained.

\section{Thermogravimetric Analysis (TGA) Measurements}

Thermal stability of samples was assessed by TGA/SDTA 851e thermogravimetric analyzer (METTLER TOLEDO, Switzerland). TGA measurements were carried out on 5-10 mg samples over a temperature range of $30-700{ }^{\circ} \mathrm{C}$ at a heating rate of $20^{\circ} \mathrm{C} / \mathrm{min}$ under nitrogen atmosphere.

\section{Tensile Test}

The tensile properties of jute/PP composites were measured by a KD111-5 microcomputer-controlled electronic universal testing machine. The samples with a dimension of $100 \mathrm{~mm}$ 
(length) $\times 20 \mathrm{~mm}$ (width) $\times 1 \mathrm{~mm}$ (thick) were fixed on the shelf of the universal testing machine. The gauge length was set at $60 \mathrm{~mm}$, and the testing speed was $2 \mathrm{~mm} / \mathrm{min}$. Five specimens for each configuration were tested and averaged.

\section{Scanning Electron Microscopy}

The fracture surfaces of the jute-reinforced composites were investigated using a SU1510 SEM (Hitachi, Japan). The surfaces were previously coated with gold to avoid charging under the electron beam.

\section{DMA}

Dynamic mechanical analysis (DMA) was performed in three-point bending mode using a DMAQ800 analyzer (TA Instrument, USA). The measurements were carried out using rectangular specimens of dimensions $60 \mathrm{~mm} \times 8 \mathrm{~mm} \times$ $1.2 \mathrm{~mm}$ (length $\times$ width $\times$ thickness) over a temperature range of $25^{\circ} \mathrm{C}$ to $150^{\circ} \mathrm{C}$. The samples were tested in a fixed frequency of $1.0 \mathrm{~Hz}$ and a heating rate of $5^{\circ} \mathrm{C} / \mathrm{min}$.

\section{Results and Discussion}

\section{FTIR Analysis}

Changes in the surface chemistry of the enzymatically modified jute fabrics were studied using FTIR spectroscopy. Figure 2 shows the comparison among the ATR-FTIR spectra of the control, PG-grafted, OG-grafted and DG-grafted jute fabric samples. Compared with the control sample, two new peaks corresponding to the saturated $\mathrm{C}-\mathrm{H}$ stretching vibrations appeared at 2922 and $2854 \mathrm{~cm}^{-1}$, which is considered to be the consequence of long alkyl chain in the alkyl gallates. These results are similar to those previously reported by Dong et al. [15]. Furthermore, the peak intensity of the saturated $\mathrm{C}-\mathrm{H}$ stretching vibrations increased gradually

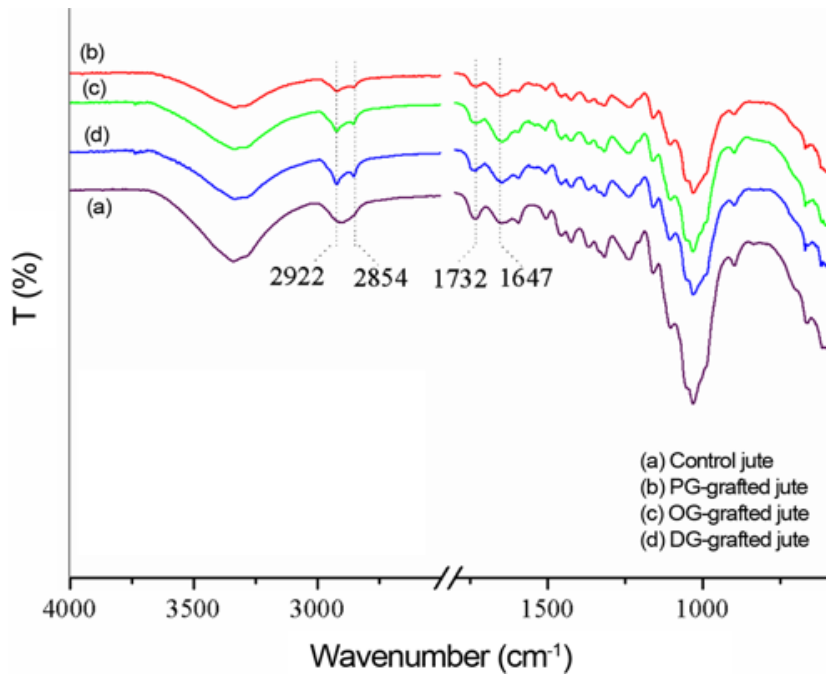

Figure 2. FTIR spectra of: control jute; PG-grafted jute; OGgrafted jute and DG-grafted jute. increasing the length of the alkyl chain of the gallates grafted. The spectrum of the alkyl gallate-grafted jute has several stronger peaks at 1732 and $1647 \mathrm{~cm}^{-1}$, which correspond to $\mathrm{C}=\mathrm{O}$ stretching vibrations. The FTIR results clearly demonstrated that the alkyl gallates have been covalently grafted onto the surface of the jute fibers by laccase.

\section{Effect of Surface Modification on Contact Angle and Wetting Time}

In order to get insight into the hydrophobic properties of jute fabric used for the fabrication of jute/PP composites, contact angles of jute fabrics were determined as mentioned in the experimental part, and the results are presented in Figure 3.

The water contact angle of the control jute fabric was found to be $106.61^{\circ}$, and the water droplet disappeared within $4 \mathrm{~s}$, showing good hydrophilicity. However, as expected for PG-grafted jute, OG-grafted jute and DG-grafted jute, water contact angle increased to $117.54^{\circ}, 121.70^{\circ}$, and $133.01^{\circ}$, respectively. Jute fabric modified with alkyl gallates exhibited an increase in wetting time and water contact angles compared to those obtained from unmodified jute. The longer the hydrocarbon chain of alkyl gallate grafted on jute was, the higher were the contact angle and wetting time. Higher contact angle value and wetting time indicated more hydrophobic nature of samples. The increased hydrophobicity of the jute fiber can be explained by the presence of long hydrocarbon chains on the surface of the jute fiber. Since the untreated jute fibers exhibit high hydrophilicity, they are inherently incompatible with hydrophobic polymer matrix materials and especially for poor interfacial adhesion between the hydrophilic jute fibers and PP [16]. Therefore, the hydrophobic modification of jute fibers could improve the interfacial adhesion, which would be conductive to the enhancement of the final mechanical behavior of composite materials [17].

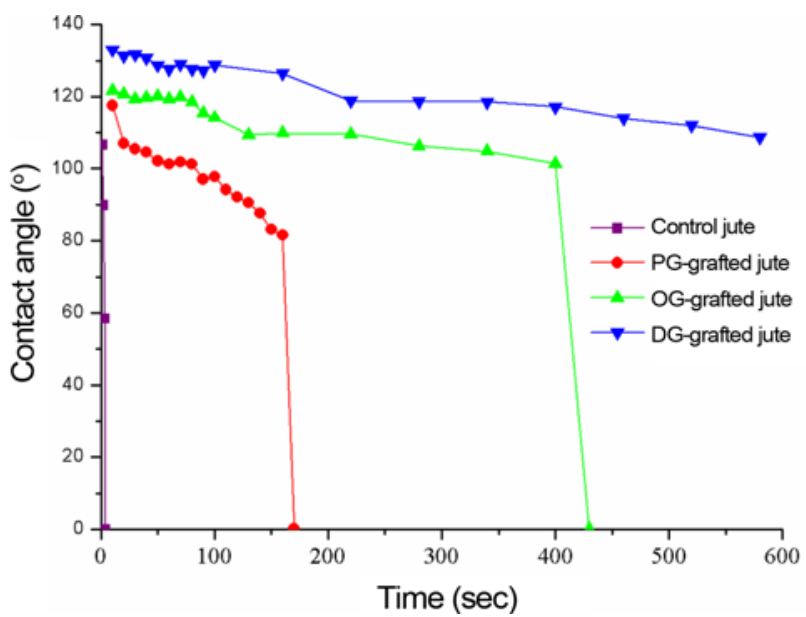

Figure 3. The time-dependent contact angle of a water drop on jute fabric samples. 


\section{Water Absorption and Thickness Swelling of the Com- posites}

Water penetration into composites can be conducted by the gaps and flaws at the interfaces between the jute fibers and polymers because of incomplete wettability and impregnation. Due to the presence of hydroxy and other polar groups of jute, the poor compatibility of hydrophilic jute and hydrophobic polypropylene results in a number of gaps and flaws and weak interfacial adhesion. Therefore, hydrophobic modification of jute fibers are necessary before using them in polymer composites $[18,19]$.

The water absorption and thickness swelling as a function of the immersion time for the jute/PP composites are shown in Figure 4 and Figure 5. It can be seen that for all the four composites investigated, water absorption and thickness swelling increased linearly with immersion time in the initial stage of the absorption process, then the increasing rate

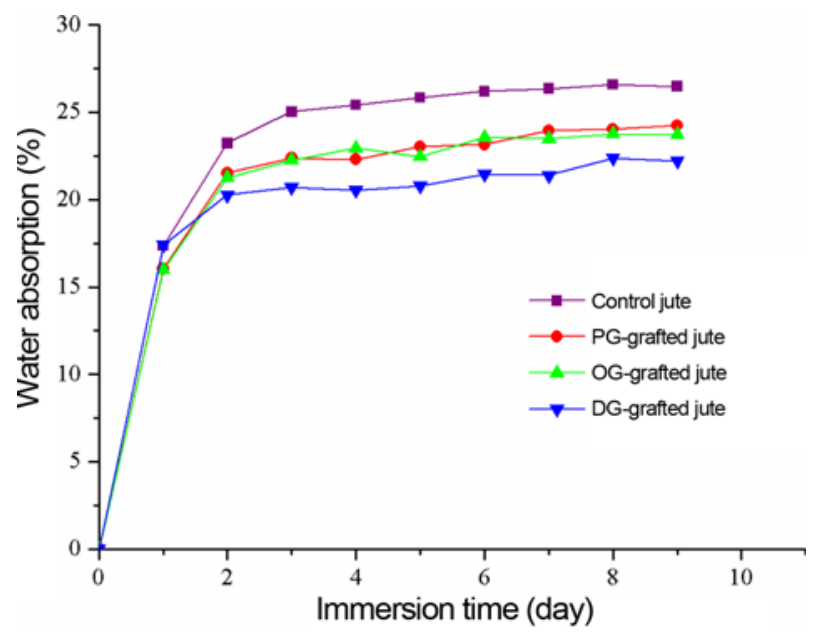

Figure 4. The water absorption as a function of the immersion time for the jute/PP composites.

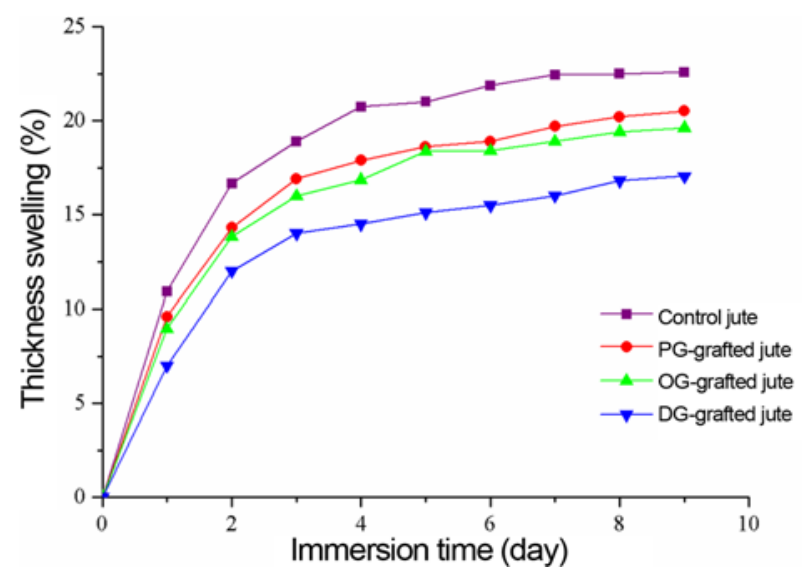

Figure 5. The thickness swelling as a function of the immersion time for the jute/PP composites. slowed down, and finally led to a plateau, corresponding to the water uptake equilibrium. This was in accord with most water absorption studies on natural fiber-reinforced composites $[20,21]$. The untreated jute/PP composite presented the highest water absorption (26.48 \%) and thickness swelling $(22.58 \%)$. As expected, all the samples modified with alkyl gallates exhibited a decrease in water absorption and thickness swelling values compared to those obtained from untreated jute/PP composites. Furthermore, a clear effect of alkyl chain length on both parameters was observed. The incorporation of DG with longer chain lengths (12 carbons) showed the lowest water absorption (22.21\%) and thickness swelling $(17.05 \%)$. The decrease in water absorption and thickness swelling were attributed to the improved interfacial adhesion that reduced water accumulation in the interfacial voids and prevented water from entering the jute fiber.

\section{Tensile Properties of the Composites}

Effective wetting and uniform dispersion of fibers in a given matrix and strong interfacial adhesion between the phases are required to obtain a composite with satisfactory mechanical properties [22]. Tensile properties can directly reflect the interfacial properties between matrix and fibers [23]. The effect of surface treatment of jute fabrics on the tensile strength, tensile modulus and elongation at break of the composites are given in Table 1.

It was observed that the control jute/PP composite showed the lowest tensile strength (34.58 MPa) and tensile modulus $(2669.57 \mathrm{MPa})$ among the different types of composite. After enzymatic modification, the tensile strength of the composites reinforced by PG-grafted, OG-grafted and DGgrafted jute fabric increased by $6.45 \%, 7.17 \%$, and $16.54 \%$, respectively. Moreover, the tensile modulus of the composites reinforced by PG-grafted, OG-grafted and DG-grafted jute fabric increased by $3.30 \%, 9.58 \%$, and $17.60 \%$ compared with that of the control one. However, the enzymatic modification almost had no effect on elongation at break. These enhancements in tensile strength and modulus indicated the effectiveness of the surface modification of the jute fabrics. The long chain molecules presented in alkyl chain of gallates interacted with PP leading to a van der waals' type of interaction. Therefore, better interfacial compatibility were obtained, which satisfied the requirement for reinforcing the composites with better mechanical properties.

Table 1. Tensile properties of the different composites

\begin{tabular}{lccc}
\hline \multicolumn{1}{c}{ Composite } & $\begin{array}{c}\text { Tensile } \\
\text { strength }(\mathrm{MPa})\end{array}$ & $\begin{array}{c}\text { Tensile } \\
\text { modulus }(\mathrm{MPa})\end{array}$ & $\begin{array}{c}\text { Elongation at } \\
\text { break (\%) }\end{array}$ \\
\hline Control jute/PP & $34.58 \pm 1.74$ & $2669.57 \pm 99.66$ & $2.59 \pm 0.11$ \\
PG-grafted jute/PP & $36.81 \pm 2.02$ & $2757.71 \pm 100.69$ & $2.51 \pm 0.04$ \\
OG-grafted jute/PP & $37.06 \pm 1.44$ & $2925.37 \pm 105.48$ & $2.57 \pm 0.13$ \\
DG-grafted jute/PP & $40.30 \pm 0.36$ & $3139.43 \pm 44.45$ & $2.78 \pm 0.30$ \\
\hline
\end{tabular}


The tensile strength and modulus of the composites before and after water immersion of $216 \mathrm{~h}$ are compared in Figure 6,7 . In general, the tensile properties of the fiber-reinforced composites are decreased after the water immersion, due to the effect of the water molecules, which change the structure and properties of the fibers, matrix and the interface between them [24]. As expected, both untreated jute/PP composites and modified jute/PP composites experienced reductions in tensile strength and modulus upon immersing in water. This

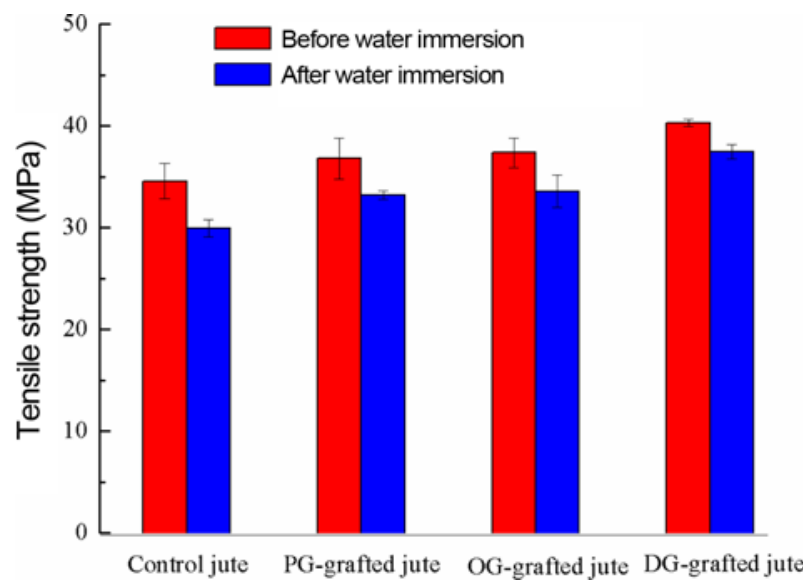

Figure 6. Tensile strength of the composites before and after water immersion of $216 \mathrm{~h}$.

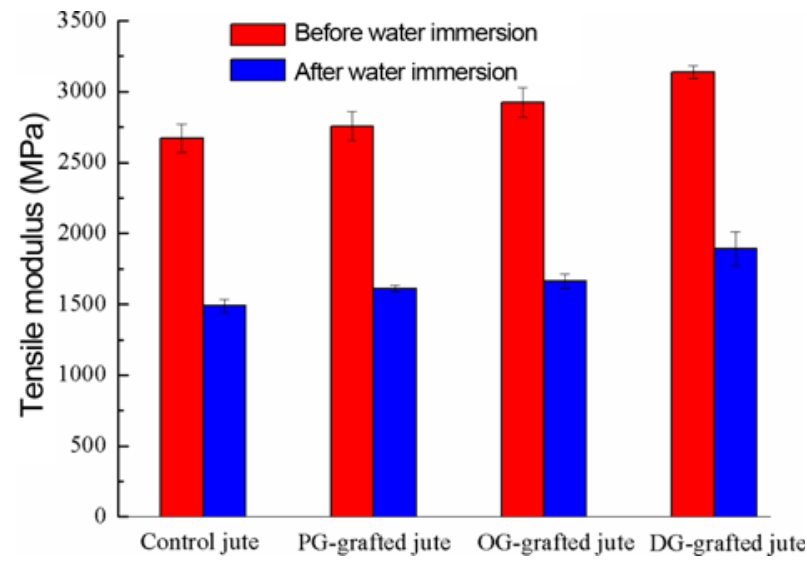

Figure 7. Tensile modulus of the composites before and after water immersion of $216 \mathrm{~h}$.

Table 2. Retention of tensile strength and modulus of the different composites after water immersion of $216 \mathrm{~h}$

\begin{tabular}{lcc}
\hline \multicolumn{1}{c}{ Composites } & $\begin{array}{c}\text { Tensile strength } \\
\text { retention }(\%)\end{array}$ & $\begin{array}{c}\text { Tensile modulus } \\
\text { retention (\%) }\end{array}$ \\
\hline Control jute/PP & $86.58 \pm 1.56$ & $55.75 \pm 0.63$ \\
PG-grafted jute/PP & $89.89 \pm 1.35$ & $56.85 \pm 1.05$ \\
OG-grafted jute/PP & $90.21 \pm 0.97$ & $58.43 \pm 1.62$ \\
DG-grafted jute/PP & $92.93 \pm 0.74$ & $60.23 \pm 2.15$ \\
\hline
\end{tabular}

could be due to the fact that the immersion of composites in water reduced the interfacial adhesion between the jute fiber and matrix and created the debonding leading to a decrease in the mechanical properties of the jute/PP composites [25]. Fortunately, all composite samples reinforced by alkyl gallatemodified jute exhibited an increase in tensile strength and modulus retention compared to those obtained from unmodified jute/PP composite (see Table 2). The increased retentions of tensile strength and modulus indicated that the existence of alkyl gallates tended to decrease moisture attack, i.e., incorporating jute fibers into the PP caused improvements in tensile strength and modulus retentions. These changes of tensile strength and modulus agreed well with the changing pattern of water absorption vs. immersion time. It was also found that the tensile strength retention for all composites were higher in comparison to the tensile modulus retention. In other words, the tensile strength of the composites tested in this work was less sensitive to water absorption.

\section{SEM Analysis of Fracture Surfaces}

As the compatibility between the jute fibers and matrix were improved, the fiber-matrix interaction increased and resulted in the development of a stronger interface. In order to corroborate this, the fracture surfaces of the composites are observed by SEM and the micrographs obtained are shown in Figure 8. In the case of unmodified jute/PP composites (Figure 8(a)), considerable fiber pull-out was visible in the fracture surface. This indicated poor interfacial adhesion and inadequate wetting of the unmodified fibers with the PP matrix. For the alkyl gallate modified jute/PP composites (Figure 8(b)-(d)), relatively higher fiber-matrix adhesion and some pull-out of fibers also were observed. The modified jute fibers were better coated by PP matrix that considerably reduced the gaps between them. It was also observed that the PP matrix were pulled out together with the jute fibers during tensile fracture. Therefore, it could be concluded that better fiber-matrix adhesion were obtained owing to the enzymatic hydrophobic modification of the jute fibers.

\section{TGA Analysis}

A thermal analysis study was necessary to determine the influence of fiber addition into polymer on the thermal stability of composites and to confirm any degradation process during composites production [26]. Thermal stability of pure $\mathrm{PP}$, composites reinforced with unmodified or modified jute fabrics is enumerated in TGA (Figure 9) and DTG (Figure 10) thermograms. Pure PP showed a one-step decomposition process, while composites clearly presented a two-step process. In the case of the PP, a major decomposition occurred from $400{ }^{\circ} \mathrm{C}$ to $500{ }^{\circ} \mathrm{C}$, and the pyrolysis of the main components in PP occurred at about $463{ }^{\circ} \mathrm{C}$ which indicated the degradation of saturated and unsaturated carbon atoms in PP [27]. For the jute/PP composites, the initial peak between $320^{\circ} \mathrm{C}$ and $390^{\circ} \mathrm{C}$ corresponded to dehydration from cellulose unit and 

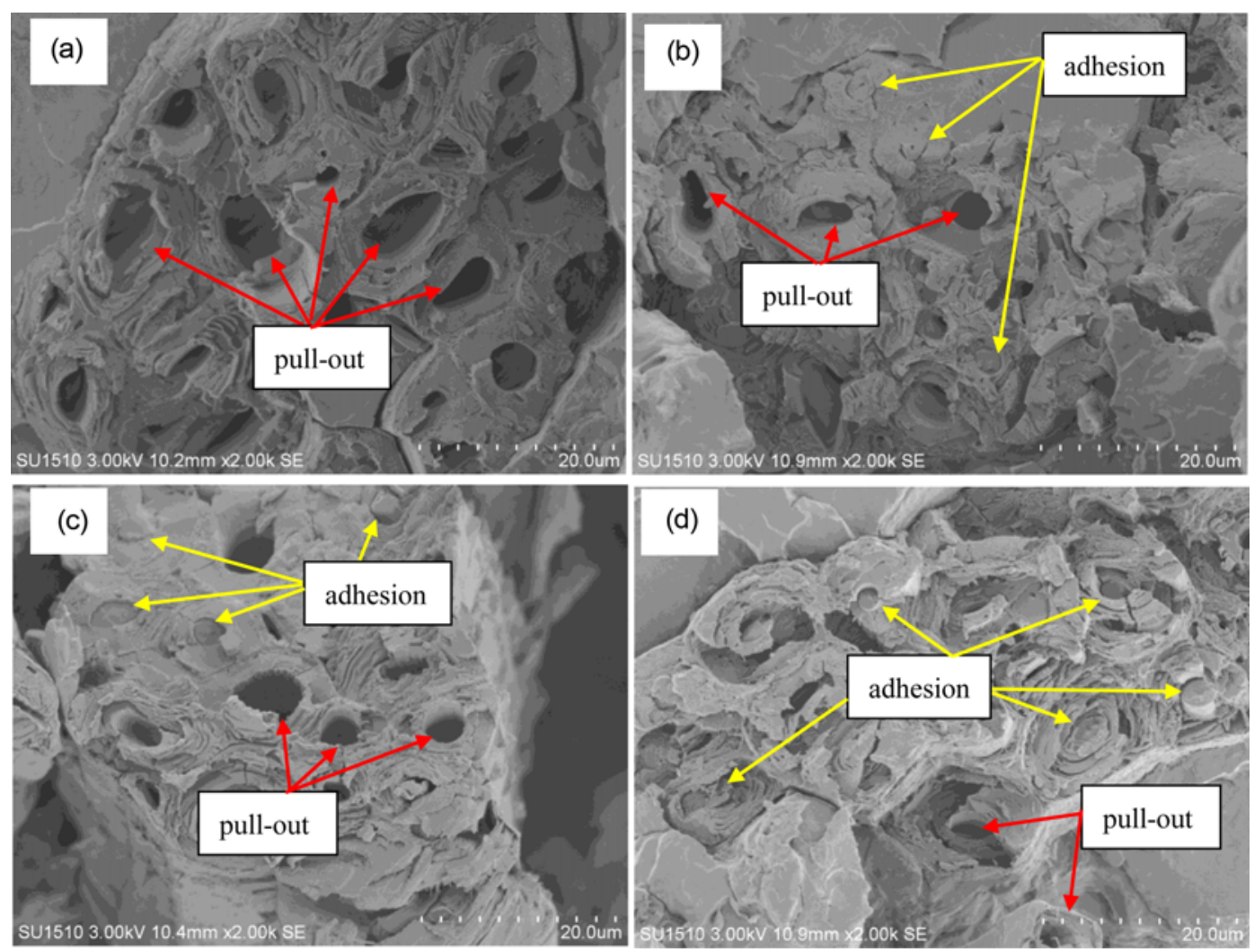

Figure 8. SEM images of the fracture sections of PP composites reinforced by (a) control jute fabric, (b) PG-grafted jute fabric, (c) PGgrafted jute fabric, and (d) DG-grafted jute fabric.

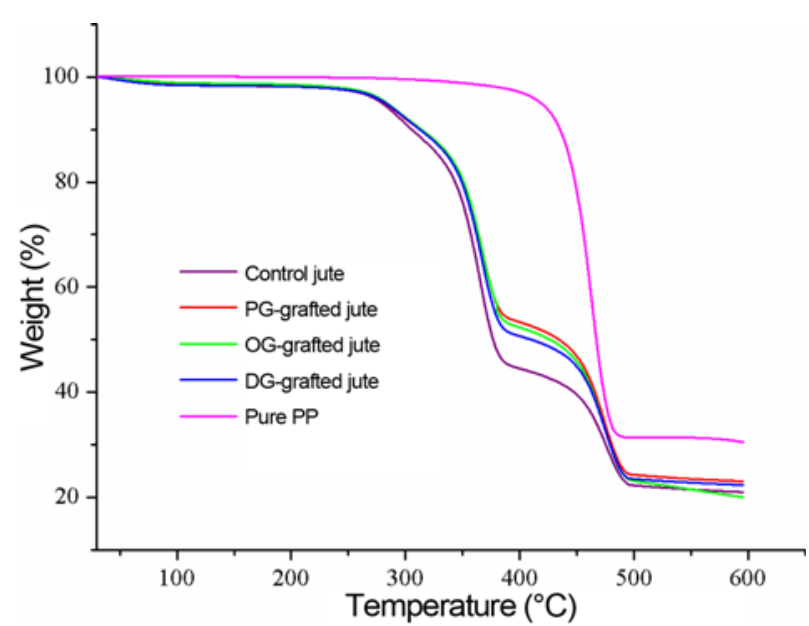

Figure 9. TGA thermogram of PP, composites reinforced with unmodified and modified jute fabrics.

thermal cleavage of glycosidic linkage by transglycoylation and scission of C-O and C-C bonds [28]. The second decompositon occurred between 400 and $500{ }^{\circ} \mathrm{C}$ indicated the degradation of PP matrix. The results revealed that the influence of the enzymatic hydrophobic modification of jute on thermal properties of the jute/PP composites was slight.

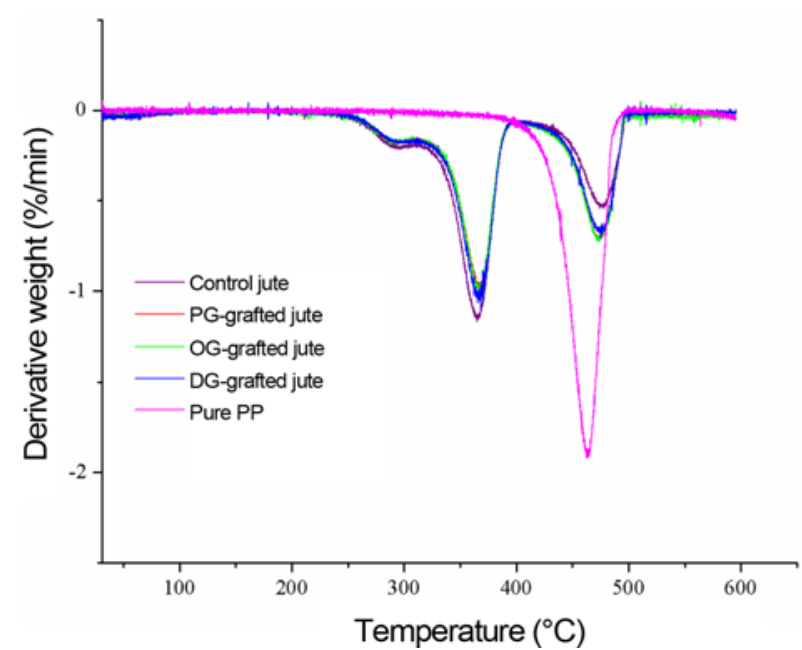

Figure 10. DTG thermogram of PP, composites reinforced with unmodified and modified jute fabrics.

From Figure 8 it is clear that the second peak in the case of jute/PP composites are shifted to higher temperature (about $10{ }^{\circ} \mathrm{C}$ ) region compared to $\mathrm{PP}$, suggesting that the thermal stability of the fiber-reinforced composites are higher than that of pure PP due to fiber/matrix interactions. 


\section{DMA Analysis}

DMA can provide reliable information over the relaxation behaviour of the materials examined [29]. In order to evaluate the effect of enzymatic hydrophobic modification on the

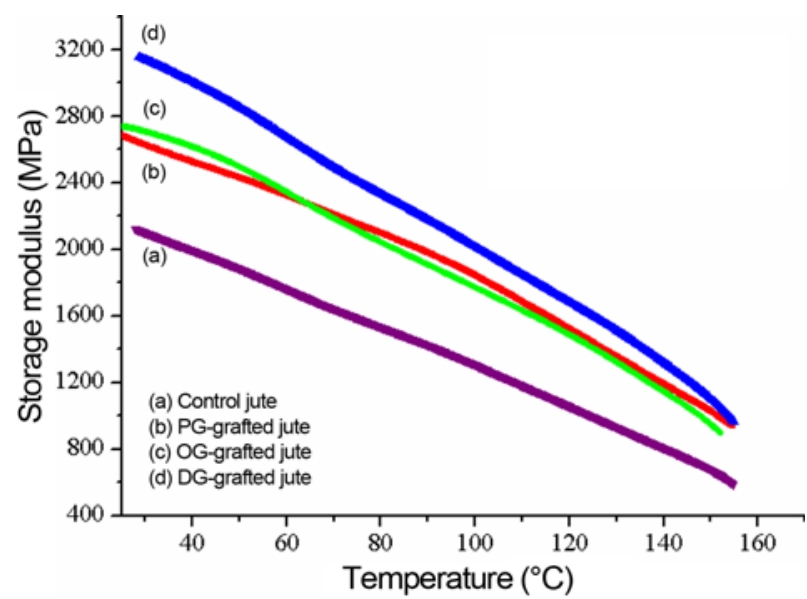

Figure 11. Storage modulus of different jute/PP composites.

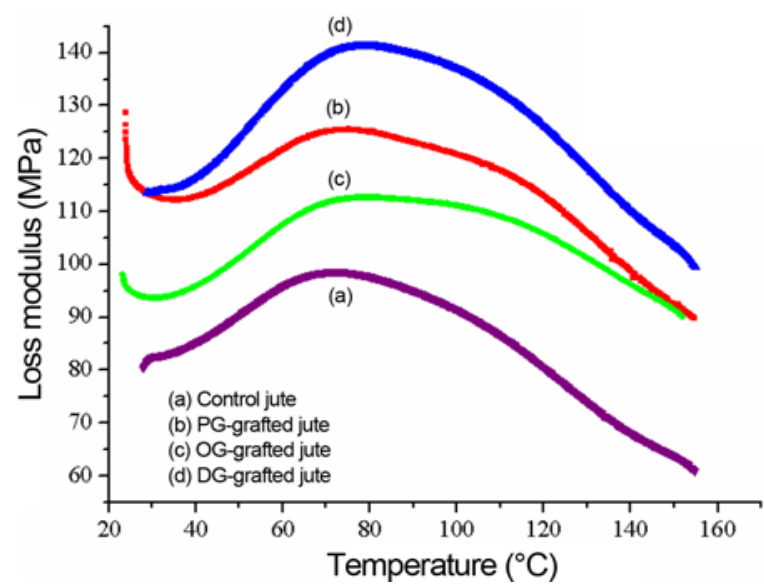

Figure 12. Loss modulus of different jute/PP composites.

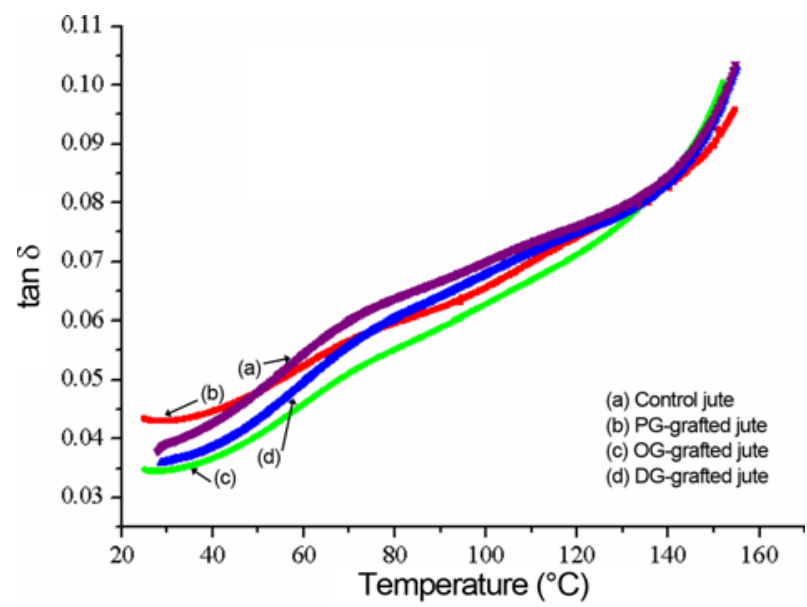

Figure 13. $\tan \delta$ of different jute/PP composites. efficiency of fiber/matrix interfacial adhesion, thermomechanical properties of the jute/PP composites were measured. The storage modulus $\left(E^{\prime}\right)$, loss modulus $\left(E^{\prime \prime}\right)$, and normalized tan $\delta$ curves of the composite samples are illustrated in Figure 11-13.

The $E^{\prime}$ is useful in assessing the molecular basis of the mechanical properties of materials because it is very sensitive to structural changes, such as fiber-matrix interfacial bonding [30]. Variation of $E^{\prime}$ as a function of temperature for jute/PP composites is graphically enumerated in Figure 11. The values of the $E^{\prime}$ for all composite samples dropped as the temperature increased. There has been a significant increase in the $E^{\prime}$ of PP composites reinforced with alkyl gallatesgrafted jute fabrics over the whole range of testing temperatures, especially for the DG-grafted jute/PP composites. This situation can be explained as a result of improved interfacial adhesion between modified jute and the PP matrix, which allowed a greater degree of stress transfer at the interface. The increase of the modulus was also observed in the tensile tests.

The loss modulus is proportional to the amount of energy that dissipated as heat by the material [31]. Figure 12 presents the loss modulus of the control and modified jute/ PP composites as a a function of temperature. The alkyl gallates-grafted jute/PP composites produced higher values of $E^{\prime \prime}$ than did the control jute/PP composites. The $E^{\prime \prime}$ peak is attributed to the mobility of the resin molecules. After the enzymatic hydrophobic modification of jute fibers, the transitional peak shifted to a higher region. In the experimental range, the $E^{\prime \prime}$ peak of control jute/PP composite appeared at $72.07^{\circ} \mathrm{C}$, and it shifted to $79.28^{\circ} \mathrm{C}$ in the DG-grafted jute/PP composite. The obtained increase in the transitional peak is probably the fact of immobilization of the polymer molecules near the surface of the modified jute fibers due to the improved interfacial adhesion.

The value of $\tan \delta$, the damping energy ratio, is an indication of the molecular motions existing in the materials [31]. The $\tan \delta$ values of untreated and alkyl gallates-grafted jute/PP composites are shown in Figure 13. $\tan \delta$ values were fairly stable at low temperature but increased rapidly at temperatures above $40^{\circ} \mathrm{C}$. The lowering of $\tan \delta$ values suggests the restraining effect of the fibers on the matrix mobility [32]. These restrictions were enhanced with enzymatic hydrophobic modification of jute. The improved interfacial adhesion tended to reduce the mobility of the molecular chain at the interface which was accordingly revealed by the decrease in $\tan \delta$ values.

\section{Conclusion}

An enzymatic method using laccases for grafting the alkyl gallates (PG, $\mathrm{OG}$ and $\mathrm{DG}$ ) on jute fabric was developed to promote its adhesion with a PP matrix. The covalent grafting of the alkyl gallates on jute was confirmed by the increased methylene and carbonyl groups in the FTIR spectra of the 
jute fabric. Contact angle and wetting time results showed that the alkyl gallates modified jute obtained excellent hydrophobilicity. Alkyl gallate treated jute/PP composites showed lower water uptake and better dimensional stability because of the higher interfacial interactions. The properties of jute/PP composites revealed that they were strongly influenced by the alkyl chain length of the gallates. The longer the hydrocarbon chain of alkyl gallate grafted on jute was, the better was the tensile and dynamic mechanical properties. Hydrophobic modification of jute by laccase did not have any significant effect on the thermal properties of the jute/PP composites. Therefore, it is believed that this surface hydrophobic modification by enzyme can be used an effective and environmentally friendly fiber modification method for the production of natural fiber-reinforced composites.

\section{Acknowledgements}

This work was financially supported by the National Natural Science Foundation of China (51173071), the Program for New Century Excellent Talents in University (NCET-12-0883), the Program for Changjiang Scholars and Innovative Research Team in University (IRT1135) and the Fundamental Research Funds for the Central Universities (JUSRP51312B, JUSRP51505).

\section{References}

1. P. Zadorecki and A. J. Michell, Polym. Compos., 10, 69 (1990).

2. H. Essabir, E. Hilali, A. Elgharad, H. El Minor, A. Imad, A. Elamraoui, and O. Al Gaoudi, Mater. Des., 49, 442 (2013).

3. X. Chen, Q. Guo, and Y. Mi, J. Appl. Polym. Sci., 69, 1891 (1998).

4. P. J. Herrera-Franco and A. Valadez-Gonzalez, Compos. Pt. A-Appl. Sci. Manuf., 35, 339 (2004).

5. H. Essabir, A. Elkhaoulani, K. Benmoussa, R. Bouhfid, F. Z. Arrakhiz, and A. Qaiss, Mater. Des., 51, 780 (2013).

6. N. E. Marcovich and M. A. Villar, J. Appl. Polym. Sci., 90, 2752 (2004).

7. J. A. Khan, M. A. Khan, and R. Islam, Fiber. Polym., 13, 1300 (2012).

8. J. A. Khan, M. A. Khan, and R. Islam, Fiber. Polym., 15, 2386 (2014).

9. A. S. Ahmed, M. S. Islam, A. Hassan, M. M. Haafiz, K. N. Islam, and R. Arjmandi, Fiber. Polym., 15, 307 (2014).
10. A. K. Chanda, A. Hazra, M. P. Kumar, S. Neogi, and S. Neogi, Fiber. Polym., 16, 902 (2015).

11. D. Ray, B. K. Sarkar, S. Das, and A. K. Rana, Comp. Sci. Technol., 62, 911 (2002).

12. H. Claus, Micron., 35, 93 (2004).

13. S. Riva, Trends Biotechnol., 24, 219 (2006).

14. K. M. G. Hossain, M. D. González, J. M. D. Monmany, and T. Tzanov, J. Mol. Catal. B-Enzym., 67, 231 (2010).

15. A. Dong, Y. Yu, J. Yuan, Q. Wang, and X. Fan, Appl. Surf. Sci., 301, 418 (2014).

16. J. M. Park, S. T. Quang, B. S. Hwang, and K. L. DeVries, Comp. Sci. Technol., 66, 2686 (2006).

17. Y. Li, Y. W. Mai, and L. Ye, Compos. Interfaces, 12, 141 (2005).

18. A. K. Mohanty, M. A. Khan, and G. Hinrichsen, Compos. Pt. A-Appl. Sci. Manuf., 31, 143 (2000).

19. Q. Lin, X. Zhou, and G. Dai, J. Appl. Polym. Sci., 85, 2824 (2002).

20. K. R. Harikumar, K. Joseph, and S. Thomas, J. Reinf. Plast. Compos., 18, 346 (1999).

21. A. Arbelaiz, B. Fernandez, J. A. Ramos, A. Retegi, R. Llano-Ponte, and I. Mondragon, Compos. Sci. Technol., 65, 1582 (2005).

22. H. Jiang and D. P. Kamdem, Appl. Surf. Sci., 256, 4559 (2010).

23. S. Kaewkuk, W. Sutapun, and K. Jarukumjorn, Compos. Pt. B-Eng., 45, 544 (2013).

24. A. Espert, F. Vilaplana, and S. Karlsson, Compos. Pt. AAppl. Sci. Manuf., 35, 1267 (2004).

25. A. Athijayamani, M. Thiruchitrambalam, U. Natarajan, and B. Pazhanivel, Mater. Sci .Eng. A-Struct. Mater. Prop., 517, 344 (2009).

26. A. Arbelaiz, B. Fernandez, J. A. Ramos, and I. Mondragon, Thermochim. Acta, 440, 111 (2006).

27. P. V. Joseph, K. Joseph, S. Thomas, C. K. S. Pillai, V. S. Prasad, G. Groeninckx, and M. Sarkissova, Compos. Pt. AAppl. Sci. Manuf., 34, 253 (2003).

28. S. Mohanty, S. K. Verma, and S. K. Nayak, Compos. Sci. Technol., 66, 538 (2006).

29. V. Vladimirov, C. Betchev, A. Vassiliou, G. Papageorgiou, and D. Bikiaris, Comp. Sci. Technol., 66, 2935 (2006).

30. M. Jacob, B. Francis, and S. Thomas, Polym. Compos., 27, 672 (2006).

31. C. K. Hong, I. Hwang, N. Kim, D. H. Park, B. S. Hwang, and C. Nah, J. Ind. Eng. Chem., 14, 71 (2008).

32. C. K. Hong and R. P. Wool, J. Appl. Polym. Sci., 95, 1524 (2005). 